\title{
Energy consumption of two-stage fine grinding of Douglas-fir wood
}

\author{
Jinwu Wang ${ }^{1}$ (D) Johnway Gao ${ }^{2} \cdot$ Kristin L. Brandt ${ }^{3} \cdot$ Michael P. Wolcott $^{3}$
}

Received: 13 October 2017 / Accepted: 2 February 2018 / Published online: 12 March 2018

(C) The Japan Wood Research Society 2018

\begin{abstract}
Fine wood powders have advantages over traditional coarse wood particles for various emerging applications. However, an efficient system to produce fine wood powders has not been well established. We investigated the comminution capability and efficiency of a two-stage grinding system consisting of a hammer mill circuit and an rotor impact mill circuit to convert wood feedstocks into fine powders. Air-dried forest harvest residuals were comminuted by the hammer mill circuit to three intermediate product sizes with geometric mean particle sizes of 1618,669 , and $316 \mu \mathrm{m}$. These intermediate products were then pulverized into fine wood powders with median particle sizes ranging from 35 to $250 \mu \mathrm{m}$. The specific energy consumption increased with the decrease of median particle sizes, with a transition at around $100 \mu \mathrm{m}$ after which the energy consumption increased exponentially. This large-scale grinding trial provides the reliable energy consumption data for design and process economic analysis of mechanical biomass preprocessing.
\end{abstract}

Keywords Coarse grinding $\cdot$ Fine grinding $\cdot$ Rotor impact mill $\cdot$ Hammer mill $\cdot$ Energy consumption $\cdot$ Size reduction

\section{Introduction}

Biomass particle size influences particle thermodynamics and hydrodynamics including heating [1, 2], drying [3], reaction rates [4], viscosity [5], transport within and between unit processes [6], and performance in additive manufacturing $[7,8]$. Under hydrothermal and thermochemical treatments, biomass particles generate internal temperature and chemical concentration gradients, leading to a heterogeneous conversion that affects product composition kinetically and thermodynamically. In the context of emerging bioconversion, grinding wood into finer particles, beyond existing wood material grinding technologies, is of economic significance.

The size reduction step is essential, but energy intensive, and should be defined, evaluated, and optimized in terms of the final product particle size, throughput rate, and energy

Michael P. Wolcott

wolcott@wsu.edu

1 Forest Products Laboratory, USDA Forest Service, Madison, WI 53726, USA

2 Global Cellulose Fibers, International Paper, Federal Way, WA 98001, USA

3 Composite Materials and Engineering Center, Washington State University, Pullman, WA 99163, USA requirements. Preprocessing of woody biomass into a target particle size can be realized either through a one-stage or multi-stage grinding such as a coarse grinding and a fine grinding. If a high ratio of size reduction is required, reduction in two or more grinding stages in series increases efficiency [9]. Coarse grinding of wood to a median particle size of about $400 \mu \mathrm{m}$ typically uses a hammer mill, which is energy efficient for this target particle size [10-12]. However, the existing wood industry does not have efficient systems in grinding wood to finer wood powders. Current niche markets that require finer wood powders are typically met through sieve classification. Hammer mills are limited by the finished particle size that can be cost-effectively achieved. The energy consumption of hammer mill grinding increases exponentially as a function of decreasing screen mesh size $[13,14]$. In addition, small apertures of the internal screen can create an unstable grinding regime through operational difficulties including screen blinding and breakage as well as overloading the motor causing spikes in the required electric current [15]. Rotor impact mills with a built-in turbine classifier are one of the most robust and efficient choices of fine grinding equipment [16]. Rotor impact mills can recirculate oversize particles and achieve finished products in the range of $95-99 \%$ less than 100 mesh $(0.15 \mathrm{~mm})$ with a mean particle diameter between 40 and $75 \mu \mathrm{m}$ [11]. Additional power 
is required for the built-in turbine classifier which increases the grinding cost.

Grinding energy consumption is a function of the particle size of feed and product affected by material characteristics, including wood species and moisture content, grinding systems, and grinding mechanisms [14]. Mills are generally designed to work in different particle size domains. Cutter mills can produce median size of 500-2000 $\mu \mathrm{m}$ wood particles at $0.06-0.2 \mathrm{kWh} / \mathrm{kg}$, refiners $200-300 \mu \mathrm{m}$ at $0.5 \mathrm{kWh} /$ $\mathrm{kg}$, and vibration media mills $35-160 \mu \mathrm{m}$ at $0.16-0.32 \mathrm{kWh} /$ $\mathrm{kg}[17,18]$. The specific energy consumption for vibration media mills is lower than that for disk refiners [19]. Esteban and Carrasco [15] reported electrical energy consumption of $0.113-0.119 \mathrm{kWh} / \mathrm{kg}$ oven-dried (OD) wood to attain a median particle size of approximately $350 \mu \mathrm{m}$ with different grinding sequences of hammer mills fitted with a $1.5-\mathrm{mm}$ screen in the last hammer mill. Many grinding energy values reported in the literature were generated with laboratory-scale mills. However, these mills are designed to attain a product size without optimization for energy efficiency. For example, the specific energy consumption (SEC) of grinding a sawdust to a median size of $233 \mu \mathrm{m}$ with a laboratory-scale rotor impact mill was $1.844 \mathrm{kWh} / \mathrm{kg}$ [16], which is $46 \%$ of the total available wood energy. These laboratory-based values have created a perception that the mechanical grinding of wood to fine powders is too energy intense to be cost-effective. Few studies have been carried out to develop routes to realize a cost-effective industrial process of fine grinding woody biomass. Energy consumption and production capacity on an industrial scale have not been available. This information barrier has hindered the understanding of a scalable process on which economic estimates can be based to evaluate commercialization of fine wood grinding.

In this study, a two-stage grinding process was used to grind softwood forest harvest residuals (FHRs) into various sized wood powders. A hammer mill was utilized to grind FHRs into three different size particles; a rotor impact mill then milled these particles into a variety of product sizes in the sub-millimeter range. The objectives of this work were to test the operability and energy efficiency of the two-stage grinding process to produce fine wood particles and to determine the intermediate particle sizes for each grinding stage that minimizes energy consumption. The hammer mill and rotor impact mill were chosen to achieve these objectives. Both mills use similar impact forces to break down the particles. The difference is in their internal classification mechanisms: a static perforated screen for the hammer mill and a dynamic turbine air classifier that enables the separation of smaller particles more efficiently in the rotor impact mill.

\section{Materials and methods}

\section{Materials}

The Douglas-fir FHRs were procured from a roadside slash pile in southwest Oregon. The slash pile was comminuted using an on-site horizontal grinder into a product passing through a $102-\mathrm{mm}$ open screen. This material was further screened with a Black-Clawson gyratory screen with a 45-mm round hole-punched plate top deck to remove "overs" and a 6 mesh $(3.35 \mathrm{~mm})$ woven-wire bottom deck to remove "fines". The accepted material was air-dried for storage [20]. A total of $687 \mathrm{~kg}$ of material was milled to determine energy consumptions for target sizes. The moisture content was $11.5 \%$, measured before the grinding. In addition to FHRs, clean Douglas-fir wood chips passing through a 25.4-mm square screen and retained on a $4.75-\mathrm{mm}$ wire screen and conditioned to an equilibrium moisture content of $11 \%$ [14] were also used in the hammer grinding. The geometric mean diameter of wood chips prior to grinding was $10.36 \mathrm{~mm}$. Initial feedstock identified throughout this paper is referred to as either FHRs or wood chips.

\section{Hammer mill grinding trials}

To obtain wood grinding data comparable to an industrial scale, a hammer mill grinding circuit consisting of a vibrating feeder, hammer mill (Bliss Eliminator Fine Grind Hammer mill, EMF-24115-TFA, Bliss Industries Inc. Ponca City, OK, USA), blower, cyclone separator, air lock discharger, and a dust collector was used to grind the FHRs and wood chips. The hammer mill has 32 pieces of swing hammer of $6.4 \times 50.8 \times 120 \mathrm{~mm}$ on a $610-\mathrm{mm}$ diameter rotor. The tip of the hammers reaches a linear speed of $115 \mathrm{~m} / \mathrm{s}$. The air flow rate of the blower is $63 \mathrm{~m}^{3} / \mathrm{min}$. The total rated power of the hammer mill circuit was $42 \mathrm{~kW}$ (Table 1). Several different sized screens were used to investigate their effect on energy consumption. A

Table 1 Specific components and power usage of the hammer mill and rotor impact mill grinding circuits

\begin{tabular}{lll}
\hline Mill parameter & $\begin{array}{l}\text { Hammer mill } \\
(\text { EMF-24115-TFA) }\end{array}$ & $\begin{array}{l}\text { Rotor impact mill } \\
\left(\text { Mikro ACM }^{\circledR} 15\right)\end{array}$ \\
\hline Rotor diameter $(\mathrm{mm})$ & 610 & 318 \\
Rotor rotation $(\mathrm{rpm})$ & 3600 & 7200 \\
Tip speed $(\mathrm{m} / \mathrm{s})$ & 115 & 116 \\
Rotor power $(\mathrm{kW})$ & 29.8 & 11.2 \\
Blower power $(\mathrm{kW})$ & 11.2 & 11.2 \\
Classifier power $(\mathrm{kW})$ & - & 1.5 \\
Feeder power $(\mathrm{kW})$ & 0.2 & 0.3 \\
Discharger power $(\mathrm{kW})$ & 0.4 & 0.3 \\
Total power $(\mathrm{kW})$ & 41.6 & 24.4 \\
\hline
\end{tabular}


Fluke 1735 Power Logger (Fluke Corporation, Everett, WA, USA) was connected to the power entry point to record the total electricity consumption for the whole circuit and grinding time [14] from which SEC and net SEC were calculated from active power. SEC is the electrical energy consumed under load per unit feed material subjected to grinding. Net SEC is the SEC less the energy consumed by idle run. The net energy is the actual energy passed to the materials for comminution, thus better reflecting the material grindability. However, the SEC reflects better the mill performance and efficiency.

\section{SEC correction}

SEC was affected by the material feed rate; a high feed rate will use less energy per unit mass than a low feeding rate. The minimum SEC was achieved when the equipment was operated at a feeding rate that matches its rated power [14], defined as the highest power input allowed to flow through the particular equipment. In a commercial grinding system, the material would be consistently fed keeping the realized power at the rated power level. However, manually feeding the mills in the laboratory was made difficult while keeping the system at the operation at the rated power. Some feeding rates were very low, leading to a low realized power. For the same amount of material, a lower feeding rate means a longer residence milling time, leading to a larger fraction of idle power in the realized power, i.e., higher SEC. Therefore, SEC was corrected to the rated power level to allow better comparisons across runs and to present information similar to what would be expected with a commercial system. One observation from actual power consumption curves was that the net energy consumption, which was used for actual comminution of material, did not change under various feeding rates [14]. Thus, the corrected SEC was obtained by the following equation:

Corrected SEC $=\frac{\text { Net SEC } \times \text { Rated power }}{\text { Rated power }- \text { Idle power }}$,

where the net SEC was obtained by subtracting idle energy consumption from SEC. The baseline idle power, which was the power consumed when the mill ran without the material in it, and rated power were 12 and $42 \mathrm{~kW}$ for the hammer grinding circuit, respectively. All runs that were completed below the full rated power were corrected in this manner to remove the power variations due to the feeding rate variations among runs.

\section{Rotor impact mill grinding trials}

A conventional hammer mill is not typically used to grind materials into fine powders. Advanced air classifiers have been combined with hammer mills to form rotor impact mills to improve the efficiency and throughput of grinding materials into fine powders [21]. A continuous grinding circuit with a feeder, blower, rotor impact mill (MikroACM $^{\circledR}$ Model 15, Hosokawa Micron Powder Systems, Summit, NJ), and an air/material separator was used to grind the wood particles into fine wood powders at the Hosokawa Micron Powder Systems in Summit, New Jersey. The specifications of the circuit are listed in Table 1. The rotor impact mill consisted of a turbine air classifier, shroud, and rotor (Fig. 1). The diameter of the rotor was $305 \mathrm{~mm}$ with eight J-type hammers sticking out an additional $6.35 \mathrm{~mm}$ from the rim of the disk leading to a tip linear speed of $116.4 \mathrm{~m} / \mathrm{s}$ at a rotation speed $7200 \mathrm{rpm}$.

The feed material was manually charged into a feed hopper of a volumetric screw feeder that metered it into a rotary airlock valve, which dropped the material into a conveyor. The material was then conveyed into the grinding chamber of the mill and mixed with the air stream supplied by a blower (Fig. 1). The high-speed rotor combined with the liner of the vertical grinding chamber generated three types of collisions that resulted in grinding: hammers to particle, particle to particle, and particle to liner. As the material was reduced in size, the air stream lifted the material toward the classifier. The rotation speed of the air classifier that was adjustable using a variable frequency drive (Allen-Bradley ${ }^{\circledR}$ PowerFlex ${ }^{\circledR}$ 40, Rockwell Automation, Milwaukee, WI, USA) together with the flow rate of air stream that was adjustable using the blower controlled particle size that could pass through the air classifier. An increase in the classifier speed and decrease in the air flow rate decreased the particle size passing through it. When the material was fine enough to pass through the classifier, it was air conveyed to the air/material separator for collection. The particles that were too coarse to pass through the classifier fell back to the grinding zone where size reduction continued.

Nineteen runs were conducted to grind the wood particles from the first stage grinding by the hammer mill into a variety of wood powder sizes. The first seven runs were conducted to determine the setup and operational parameters for the rotor impact mill to achieve minimum attainable sizes of wood powders by feeding in the FHRs wood particles through a $0.69-\mathrm{mm}$ circular screen of the hammer mill. The final twelve runs tested the effect of different wood particle sizes that passed through the 0.69-, 3.175-, or 12.7-mm screens of the hammer mill, labeled as FHRs-1, FHRs-2, and FHRs-3, respectively. For each run, the weight, timing, and the current were recorded for the feed rate $(\mathrm{OD} \mathrm{kg} / \mathrm{h})$ and energy consumption calculation $(\mathrm{kWh} / \mathrm{OD} \mathrm{kg})$. 


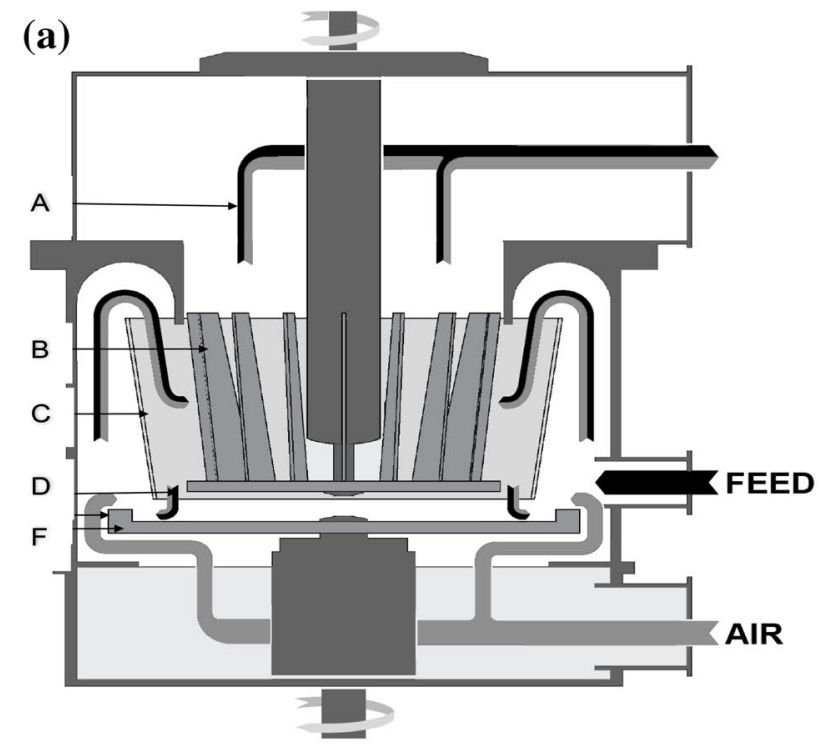

(b)

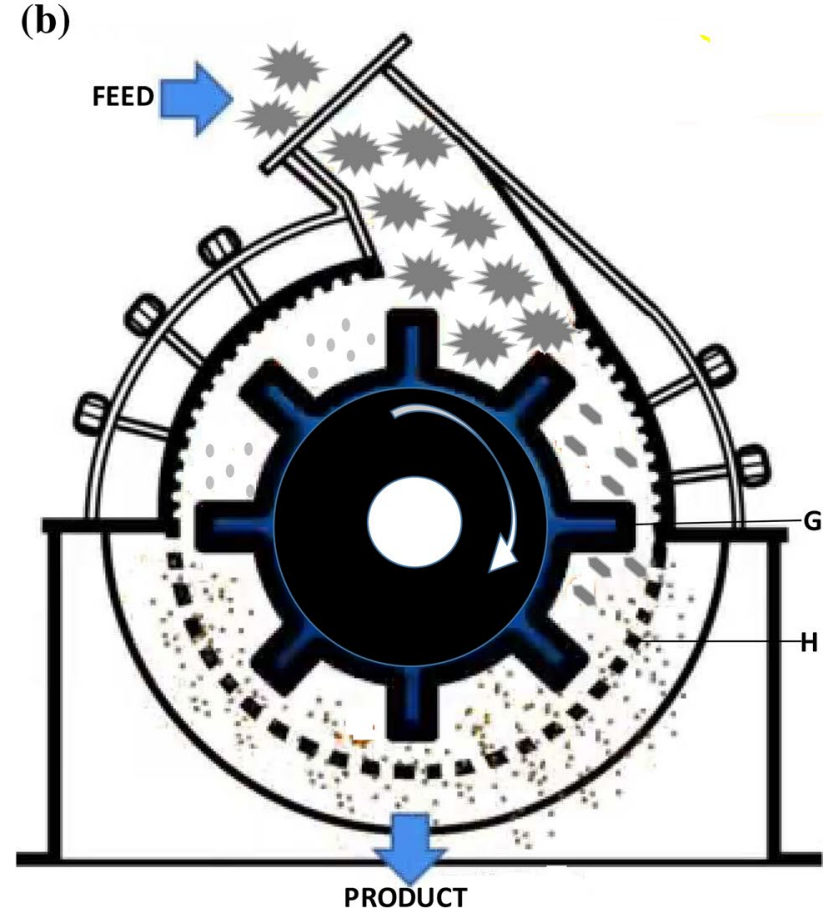

Fig. 1 a Schematic of operational mechanism of the rotor impact mill. A: fine particle stream escaping out of the grinding zone through the classifier, B: turbine air classifier, C: shroud, D: coarse particle stream falling back to the grinding zone, E: hammers, and F: rotor. b Schematic of the hammer mill. G: hammer, H: screen

\section{SEC measurement}

For the rotor impact mill, three variable-frequency drives were used to transform supply voltage $(480 \mathrm{~V})$ and frequency $(60 \mathrm{~Hz})$ into a voltage and frequency that were varied to change the rotation speeds of the rotor, classifier, and blower. The voltage/frequency $(\mathrm{V} / \mathrm{Hz})$ was held constant at approximately 7.7 for the $460 \mathrm{~V}$ motors in the range of $0-60 \mathrm{~Hz}$; the voltage was held constant above the $60 \mathrm{~Hz}$ frequency. The amperage and frequency to the motors of the rotor, classifier, and blower were recorded under load and idle runs. The rotation speeds of the rotor and classifier were measured by a tachometer. The consumed electrical energy was calculated by the formula of $\sqrt{ } 3 \times V \times I \times \mathrm{PF} \times t$ for 3-phase delta connection, where $V$ is the line voltage, $I$ the line current, PF the power factor, and $t$ the grinding time. When the frequency was less than $60 \mathrm{~Hz}$, the voltage equaled to $7.7 \times$ (frequency value in $\mathrm{Hz}$ ); when the frequency was above $60 \mathrm{~Hz}$, the voltage was the supply voltage, measured as $472.5 \mathrm{~V}$.

\section{Particle characterization}

The moisture content of the hammer mill ground wood particles was determined by 24 -h oven drying at $105^{\circ} \mathrm{C}$. Moisture analysis was conducted on select rotor impact mill ground samples with a Sartorius MA30 at $105^{\circ} \mathrm{C}$. Wet-basis moisture content is reported as the average of triplicate measurements of the sample after grinding.

Particle sizes were measured either by sieve analysis, for coarse particle size, or laser scattering particle size analysis, for fine particles. Sieve analysis was used to measure the geometric mean diameter of the hammer mill feedstock and products per ASAE 319.3 [22]. The median and mean particle size of wood powders were measured with a laser scattering particle size analyzer (Malvern Mastersizer 3000, Malvern Instruments Limited, Malvern, UK) using air as the conveying medium. A powder characteristics tester (Hosokawa Model PT-X, Hosokawa Micron Powder Systems, Summit, NJ, USA) was used to measure the aerated and tapped bulk densities of select samples. The aerated bulk density is a measure of random loose packing of a powder determined by allowing the dispersed powder to settle in a container under the influence of gravity. The tapped bulk density was obtained by tapping the container holding the aerated sample [23]. Bulk density is a key parameter in designing material transport processes.

\section{Grinding performance evaluation}

The energy consumption $\left(\mathrm{SEC}_{\mathrm{f} \rightarrow \mathrm{p}}\right)$, feed size $\left(x_{\mathrm{f}}\right)$, and product size $\left(x_{\mathrm{p}}\right)$ have been correlated by three comminution laws: Rittinger (Eq. 2), Kick (Eq. 3), and Bond (Eq. 4) laws, where $C$ is the comminution constant:

Rittinger $\quad \mathrm{SEC}_{\mathrm{f} \rightarrow \mathrm{p}}=C_{\mathrm{R}}\left(\frac{1}{x_{\mathrm{p}}}-\frac{1}{x_{\mathrm{f}}}\right)$,

Kick $\quad \operatorname{SEC}_{\mathrm{f} \rightarrow \mathrm{p}}=C_{\mathrm{K}}\left(\frac{x_{\mathrm{f}}}{x_{\mathrm{p}}}\right)$, 
Bond $\quad \mathrm{SEC}_{\mathrm{f} \rightarrow \mathrm{p}}=C_{\mathrm{B}}\left(\frac{1}{\sqrt{x_{\mathrm{p}}}}-\frac{1}{\sqrt{x_{\mathrm{f}}}}\right)$.

These laws apply to different material breakage based on the material fracture characteristics. Bond's law has been widely used for brittle mineral materials [24], while von Rittinger's law was found to be appropriate for woody biomass [25]. Rittinger's law states that the energy required for breaking a material is proportional to the new surface created [26]. Under this law, breaking efficiency is constant for a given mill and material and independent of the sizes of the feed and product. Kick proposed that the work required for breaking a given mass of material is constant for the same reduction ratio of the feed size to the product size [27]. Bond's law is based on the theory that the work input is proportional to the new crack tip length produced in particle breakage [28]. When experimental data are fit to the comminution laws correlating size reduction to energy consumption, the scattered data can be reduced to a comminution constant, $C$, which facilitates comparison. When the same mill is used, the constants reflect material grindability. However, when the same material is ground in multiple mills, the constants reflect mill performance.

\section{Results and discussion}

\section{Hammer mill grinding trials}

Figure 2 shows the power consumption and the duration of grinding $36 \mathrm{~kg}$ of wood chips and $136 \mathrm{~kg}$ of the FHRs with a $0.69-\mathrm{mm}$ screen logged with the Fluke 1735 Power Logger. Most of the material was collected from the discharger at the bottom of the cyclone separator. However, 6.6-18.6\% of the material was lost in the system, mainly entrained in

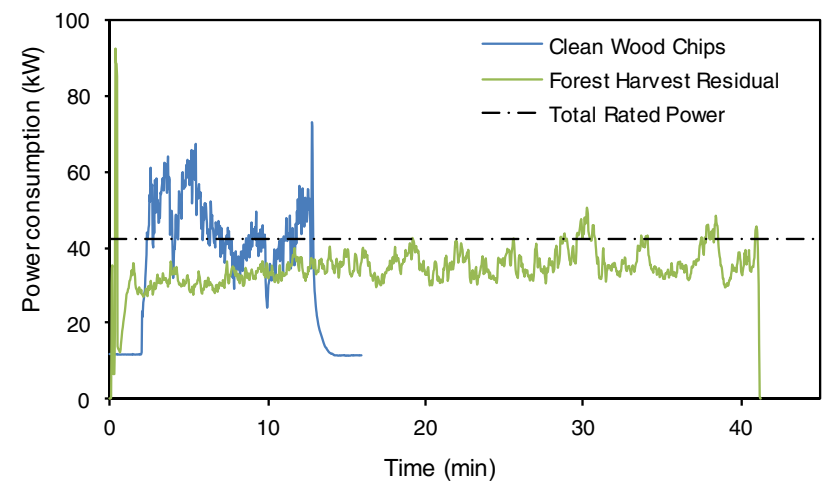

Fig. 2 Power consumption of the hammer mill circuit for grinding chips and FHRs to pass through a screen with $0.69-\mathrm{mm}$ circular holes the exhaust air of the cyclone separator or captured by a downstream dust collector. Data shows that approximately $25 \mathrm{~s}$ into the run of grinding FHRs (Fig. 2), the drawn power spiked to more than double the rated power. The grinding regime appears to become stable around 2 min into the grinding. When the duration of these power spikes lasted longer, the hammer mill automatically shut down. The chips were more homogeneous than the FHRs and they did not create overloading although they ran at a higher average power level with a $0.69-\mathrm{mm}$ screen.

The hammer mill grinding circuit ran near the total rated power of $42 \mathrm{~kW}$ for the wood chip grinding. The SEC was $0.250 \mathrm{kWh} / \mathrm{OD} \mathrm{kg}$ wood. The net SEC, calculated by subtracting the energy input of idle run from the SEC, was $0.186 \mathrm{kWh} / \mathrm{OD} \mathrm{kg}$, or $74 \%$ of the SEC. The ratio of the net SEC and SEC is an important parameter for evaluating grinding efficiency. For the wood chips, this ratio indicates about a quarter of the energy input was consumed in driving machine itself. The actual SEC and net SEC was 0.23 and $0.14 \mathrm{kWh} / \mathrm{OD} \mathrm{kg}$ wood for grinding the FHRs, respectively, or $59 \%$ of the energy input was used for grinding, which is lower than that for wood chip grinding. This is because the grinding of the FHRs was run at a lower drawn power than the rated power (Fig. 2) resulting from a low feeding rate. After correcting to the rated power, the SEC was $0.19 \mathrm{kWh} /$ OD kg wood, i.e., a grinding efficiency of $72 \%$ (Table 2).

As expected, Fig. 3 illustrates that the actual SEC was higher than the corrected energy and included an irregular trend. Some feeding rates were very low, leading to a low realized power and high SEC. For example, the actual and net SECs were 0.141 and $0.050 \mathrm{kWh} / \mathrm{OD} \mathrm{kg} \mathrm{wood,} \mathrm{respec-}$ tively for a 3.175-mm screen run (Fig. 3). This translates into $64 \%$ of the energy input that was used for the idle run. After correction, the corrected SEC dropped to $0.071 \mathrm{kWh} /$ OD kg wood with an assumption that the net SEC was still held to be $0.050 \mathrm{kWh} / \mathrm{OD} \mathrm{kg}$. This lowers the percent of the energy input to operate the idle machine to $29 \%$. Generally, the corrected SECs of grinding FHRs are comparable with those of the scots pine wood chips grinding with constant power [15]. The corrected SEC also agrees with the reported value of $0.02 \mathrm{kWh} / \mathrm{OD} \mathrm{kg}$ for grinding wood chips to a $12.7-\mathrm{mm}$ screen size by a hammer mill [29]. However, SEC values obtained with small lab mills consumed 3 to 50 times [14] as much energy as those reported here. The larger energy consumption in those investigations might be largely explained by low feeding rates and low grinding efficiency that is defined as the ratio of net SEC to total SEC.

The increased feed rate, which translated into increased charge of the grinding zone and increased realized power, did not significantly alter the product size at two different feeding rates as shown by two replicates with a screen size of $3.175 \mathrm{~mm}$ (Fig. 4). This is consistent with the observation that there was a plateau of feeding rates at which the product 
Table 2 Hammer mill performance and product characteristics of hammer-milled batches, FHRs-1, FHRs-2, and FHRs-3

\begin{tabular}{|c|c|c|c|c|}
\hline \multirow[t]{2}{*}{ Parameters } & \multirow[t]{2}{*}{ Wood chips } & \multicolumn{3}{|c|}{ Forest Harvest Residuals (FHRs) } \\
\hline & & FHRs-1 & FHRs-2 & FHRs-3 \\
\hline Geometric mean diameter (mm) & 10.36 & 7.81 & 7.81 & 7.81 \\
\hline Sample weight (kg) & 37 & 344 & 235 & 109 \\
\hline Feed moisture content $(\%)$ & 11 & 8.2 & 9.7 & 10.9 \\
\hline Screen size (mm) & 0.69 & 0.69 & 3.175 & 12.7 \\
\hline Corrected SEC, (kWh/kg OD) & 0.25 & 0.19 & 0.066 & 0.019 \\
\hline Net SEC (kWh/kg OD) & 0.17 & 0.14 & 0.048 & 0.014 \\
\hline Product median size $(\mu \mathrm{m})$ & 229 & 270 & - & - \\
\hline Geometric mean diameter $(\mu \mathrm{m})$ & 295 & 316 & 669 & 1618 \\
\hline Throughput (OD kg/h) & 180 & 145 & 446 & 397 \\
\hline
\end{tabular}

$S E C$ specific energy consumption, $O D$ oven dried

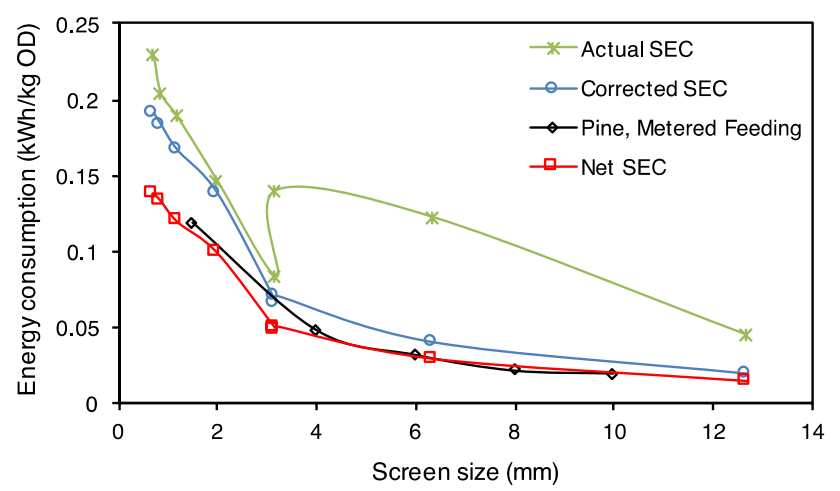

Fig. 3 Actual, corrected, and net specific energy consumptions (SEC) for FHRs compared to those for scots pine obtained under constant power [15]

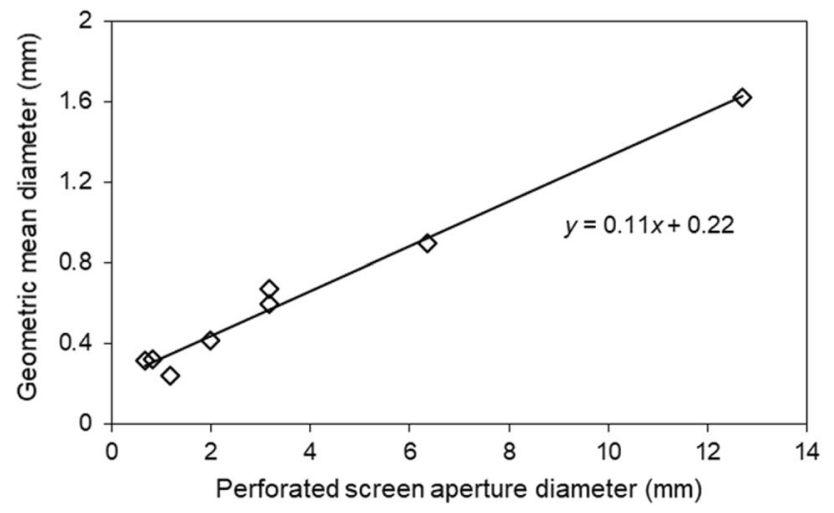

Fig. 4 Correlation of the screen aperture size and product geometric mean diameter measured using sieve analysis

size distributions were constant [30]. Screen size was the predominant controlling factor for product size; these variables have a linear relationship (Fig. 4). Figure 3 shows that the SEC increases exponentially as the product size drops, which is consistent with other investigations [13, 14]. It was observed that grinding the FHRs in a single stage from the feedstock to the $0.69-\mathrm{mm}$ screen size caused blinding and breakage of the screen and overloaded the mill motor, making this regime unsuitable for industrial application. With a wood chip size of feedstocks, the $0.69-\mathrm{mm}$ screen was the smallest screen that could be used for a stable operation. The $0.69-\mathrm{mm}$ screen ran well with a smaller comminution ratio. Esteban and Carrasco have also observed that a large comminution ratio with a small aperture screen resulted in unstable grinding [15].

Figure 5 shows Rittinger's comminution law fitted with the hammer mill grinding data for FHR. Rittinger's comminution constant is $58.6 \mathrm{kWh} \cdot \mu \mathrm{m} / \mathrm{OD} \mathrm{kg}$. The empirical equation from the hammer mill used in this study might be used to roughly estimate the energy consumption of size reduction for similar hammer mills but it might not be appropriate for other types of mills.

\section{Rotor impact mill grinding trials}

The rotor impact mill was investigated for grinding the wood particles obtained with the hammer mill into fine powders. The sizes and characteristics of the wood particles used for the rotor impact grinding trials are the three FHRs summarized in Table 2. The change of the SEC of 19 runs with median particle size is shown in Fig. 6. The attainable minimum particle size was approximately $30 \mu \mathrm{m}$. The energy consumption increased exponentially with decreasing median particle size with a transition point at around $100 \mu \mathrm{m}$ and $0.5 \mathrm{kWh} / \mathrm{OD} \mathrm{kg}$ of wood. This indicates that the rotor impact mill grinding would not be practical for a target size below $100 \mu \mathrm{m}$. Figure 7 shows Rittinger's comminution law fitting to the data of three feed sizes and nineteen product sizes and corresponding SECs from rotor impact mill grinding. The Rittinger constant of 104.5 for the rotor 


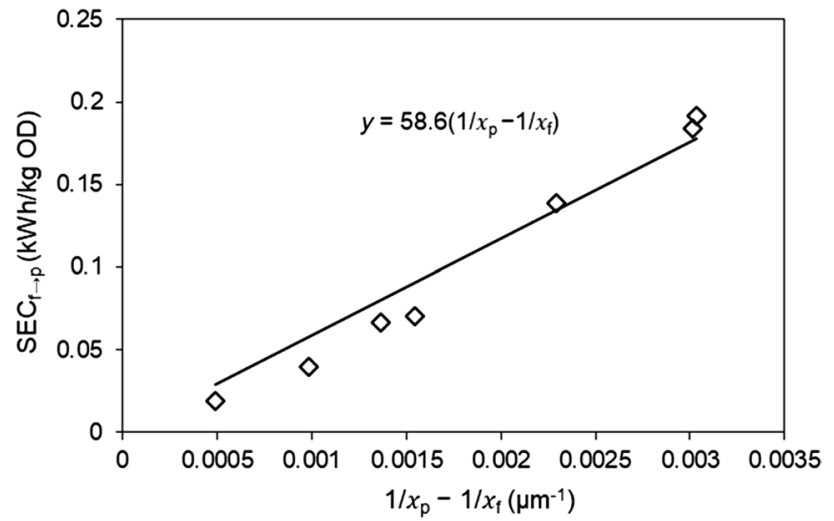

Fig. 5 Correlation of the corrected specific energy consumption with the difference of inverse geometric mean diameters of feed and product with Rittinger's comminution law for the hammer mill

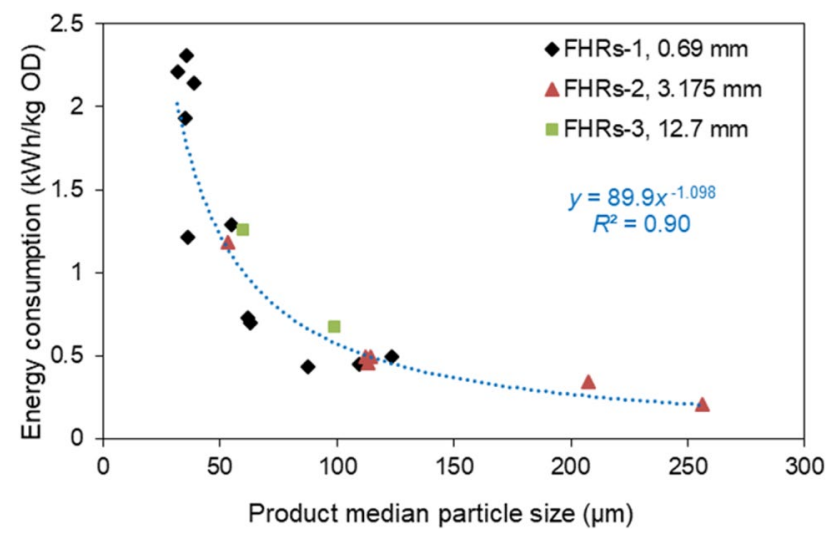

Fig. 6 The specific energy consumption changes with the median product size for three different feed sizes with the rotor impact mill

impact mill grinding is larger than 58.6 for the hammer mill grinding (Fig. 5), indicating that the hammer mill used less energy than the rotor impact mill for similar size reduction. However, it should be noted that they were not operated in the similar grinding regime; the rotor impact mill had a finer target product size. The hammer mill was not as effective as the rotor impact mill in delivering fine wood powders. The data points shown in the high size reduction end in Fig. 7 scatters more than those located at the low size reduction end indicating that Rittinger's law fits better for the low size reduction, i.e., it would not be a good predictor of SEC for low target product size and large feed size. The SEC and size reduction did not fit Kick's or Bond's law well; the coefficients of variations were low and thus are not discussed.

Table 3 summarizes the select product characteristics of the wood powders after processing through both the hammer mill and rotor impact mill. The aerated bulk density of the products did not vary with the particle size. Tapped bulk density and compressibility, which is defined as the ratio of

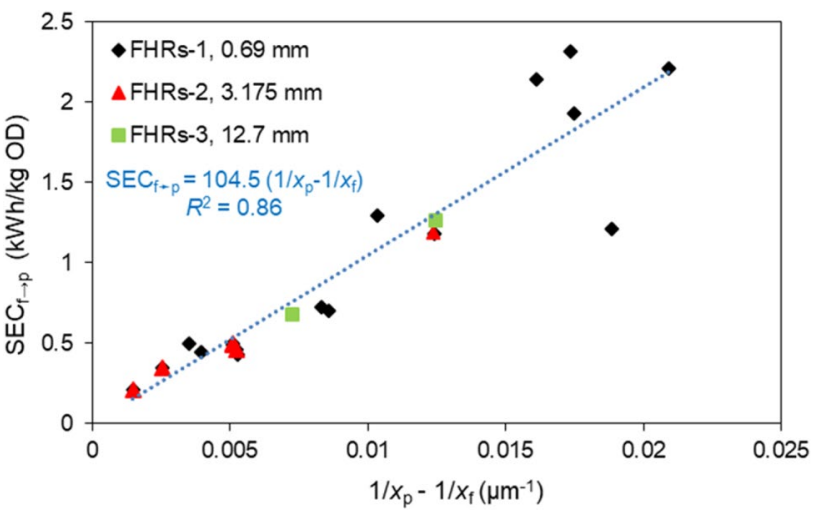

Fig. 7 Correlation of energy consumption and size reduction with Rittinger's comminution law for rotor impact mill grinding

tapped density to aerated bulk density, both increased with decreasing particle size in the range tested. Compressibility measures the propensity of the powder to settle. Fine particles such as those less than $100 \mu \mathrm{m}$ tend to be more cohesive and therefore less free-flowing and settle more, whereas the larger particles tend to be more free-flowing in the tested size range.

\section{Two-stage grinding total energy consumption}

Figure 8 shows the added total SEC of hammer mill grinding and rotor impact mill grinding to reduce initial feedstock FHRs to different final median sizes through three intermediate sizes. No difference was apparent with respect to the effect of the intermediate size on the total SEC. Twostage grinding used similar energy for target sizes at around $250 \mu \mathrm{m}$ as a one-stage hammer mill grinding operation (FHRs-2, $3.175 \mathrm{~mm}+\mathrm{RIM}$ vs. Hammer mill, $0.69 \mathrm{~mm}$ in Fig. 8). However, the combination of two mills provided a more stable grinding regime in delivering finer products. The hammer mill alone could not produce finer wood particles reliably because the small screen was often blinded and the electric current spiked to high levels leading to the motor stopped working. The total combined energy consumption increased with decreasing product size with a transition point at approximately $100 \mu \mathrm{m}$ after which the energy consumption increased exponentially, mimicking the energy information for the rotor impact mill alone (Fig. 6).

\section{Summary and conclusions}

Fine wood powders have been reported to facilitate the utilization of biomass in co-firing, thermochemical and biochemical conversions, and additive manufacturing in various publications. This study found that a two-stage 
Table 3 The specific energy consumption (SEC) and product characteristics for forest harvest residuals (FHRs) ground with the rotor impact mill

\begin{tabular}{llllllll}
\hline Feedstock & FHRs-1 & & & FHRs-2 & \multicolumn{3}{c}{ FHRs-3 } \\
\hline Sample weight $(\mathrm{kg})$ & 9 & 80 & 80 & 80 & 9 & 5 & 9 \\
Median size $(\mu \mathrm{m})$ & 35 & 55 & 87 & 114 & 256 & 60 & 99 \\
Mean size $(\mu \mathrm{m})$ & 49 & 74 & 118 & 151 & 335 & 77 & 127 \\
Product MC $(\%)$ & 3.4 & 3.6 & 4.4 & 4.0 & 6.8 & 4.04 & 4.9 \\
Aerated density $\left(\mathrm{kg} / \mathrm{cm}^{3}\right)$ & 0.16 & 0.16 & 0.17 & 0.15 & 0.19 & 0.14 & 0.14 \\
Tapped density $\left(\mathrm{kg} / \mathrm{cm}^{3}\right)$ & 0.34 & 0.33 & 0.31 & 0.26 & 0.26 & 0.28 & 0.27 \\
Compressibility & 2.17 & 2.02 & 1.76 & 1.73 & 1.39 & 2.03 & 1.88 \\
SEC $(\mathrm{kWh} / \mathrm{kg} \mathrm{OD})$ & 2.31 & 1.29 & 0.43 & 0.50 & 0.21 & 1.26 & 0.68 \\
Throughput $(\mathrm{OD} \mathrm{kg} / \mathrm{h})$ & 9 & 17 & 50 & 45 & 110 & 17 & 31 \\
\hline
\end{tabular}

$M C$ moisture content, $S E C$ specific energy consumption, $O D$ oven dried

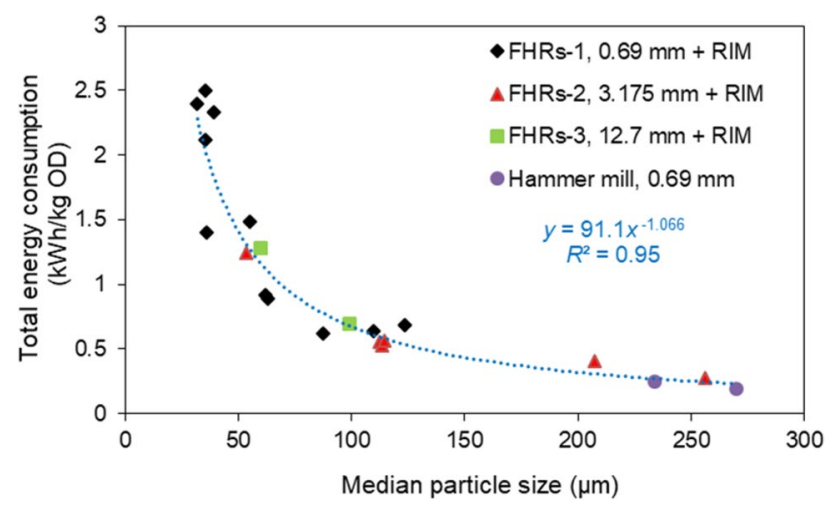

Fig. 8 Total specific energy consumption of the two-stage grinding changes with final median product size. RIM rotor impact mill

grinding process with coarse grinding completed with a hammer mill, followed by fine grinding with a rotor impact mill was an effective process to reduce FHRs into fine wood powders, compared to traditional one-stage process. The two-stage grinding process took advantages of the hammer mill and rotor impact mill to overcome each mill's limitation by utilizing their strengths: the hammer mill's low-energy and high-volume production capacity in the coarse grinding and the rotor impact mill's fine grinding capability. The SEC and size reduction correlate well with the Rittinger comminution law, but the relationship was not well described by either Kick's or Bond's comminution laws. A transition point in the total energy consumption against final median particle size curve was observed at approximately $100 \mu \mathrm{m}$ after which the energy consumption increased exponentially with decreasing particle size. It can be concluded that the two-stage grinding combining a hammer mill and a rotor impact mill extends the effective grinding regime to approximately $100 \mu \mathrm{m}$ with an energy input at $0.67 \mathrm{kWh} / \mathrm{kg}$ OD based on the fitting equation in Fig. 8.
Acknowledgements We thank Jinxue Jiang, Yalan Liu, Lanxing Du, $\mathrm{Yu} \mathrm{Fu}$, Vincent McIntyre, John Barth, and Kelly Welsch for collecting the grinding data and size analysis for the hammer mill grinding; Marc Cavaliere, Assistant Manager of Hosokawa Micron Powder Systems for the rotor impact mill grinding trials; and Dane Camenzind for drawing the ACM schematic diagram. The authors gratefully acknowledge the Northwest Advanced Renewables Alliance (NARA), supported by the Agriculture and Food Research Initiative Competitive Grant No. 201168005-30416 from the USDA National Institute of Food and Agriculture, for funding the most part of this work, and the Joint Center for Aerospace Technology Innovation of Washington State for funding a part of this work.

\section{References}

1. Papadikis K, Gu S, Bridgwater AV (2010) Computational modelling of the impact of particle size to the heat transfer coefficient between biomass particles and a fluidised bed. Fuel Process Technol 91:68-79

2. Simmons GM, Gentry M (1986) Particle size limitations due to heat transfer in determining pyrolysis kinetics of biomass. J Anal Appl Pyrolysis 10:117-127

3. Lu H, Robert W, Peirce G, Ripa B, Baxter LL (2008) Comprehensive study of biomass particle combustion. Energy Fuels 22:2826-2839

4. Dasari RK, Berson RE (2007) The effect of particle size on hydrolysis reaction rates and rheological properties in cellulosic slurries. Appl Biochem Biotechnol 137:289-299

5. Rezania S, Ye Z, Berson RE (2009) Enzymatic saccharification and viscosity of sawdust slurries following ultrasonic particle size reduction. Appl Biochem Biotechnol 153:103-115

6. Vaezi M, Pandey V, Kumar A, Bhattacharyya S (2013) Lignocellulosic biomass particle shape and size distribution analysis using digital image processing for pipeline hydro-transportation. Biosyst Eng 114:97-112

7. Henke K, Treml S (2013) Wood based bulk material in 3D printing processes for applications in construction. Eur J Wood Wood Prod 71:139-141

8. Wimmer R, Steyrer B, Woess J, Koddenberg T, Mundigler N (2015) 3d printing and wood. Ligno 11:144-149

9. Silva GGD, Couturier M, Berrin J-G, Buleon A, Rouau X (2012) Effects of grinding processes on enzymatic degradation of wheat straw. Bioresour Technol 103:192-200 
10. Gil M, Arauzo I (2014) Hammer mill operating and biomass physical conditions effects on particle size distribution of solid pulverized biofuels. Fuel Process Technol 127:80-87

11. Heimann M (2014) High speed hammermills for fine grinding: part 1-introduction. In: FeedMachinery.com. http://www.feedm achinery.com/articles/feed_technology/hammermill1/. Accessed 23 Dec 2014

12. Pandya TS, Srinivasan R (2012) Effect of hammer mill retention screen size on fiber separation from corn flour using the Elusieve process. Ind Crops Prod 35:37-43

13. Gil M, Gonzalez A, Gil A (2008) Evaluation of milling energy requirements of biomass residues in a semi-industrial pilot plant for co-firing. In: Proceedings 16th European Biomass Conference and Exhibition, Valencia

14. Liu Y, Wang J, Wolcott MP (2016) Assessing the specific energy consumption and physical properties of comminuted Douglas-fir chips for bioconversion. Ind Crops Prod 94:394-400

15. Esteban LS, Carrasco JE (2006) Evaluation of different strategies for pulverization of forest biomasses. Powder Technol 166:139-151

16. Karinkanta P, Illikainen M, Niinimäki J (2012) Pulverisation of dried and screened Norway spruce (Picea abies) sawdust in an air classifier mill. Biomass Bioenergy 44:96-106

17. Kobayashi N, Guilin P, Kobayashi J, Hatano S, Itaya Y, Mori S (2008) A new pulverized biomass utilization technology. Powder Technol 180:272-283

18. Kobayashi N, Sato T, Okada N, Kobayashi J, Hatano S, Itaya Y, Mori S (2007) Evaluation of wood powder property pulverized by a vibration mill. J Jpn Inst Energy 86:730-735

19. Gravelsins RJ (1998) Studies of grinding of wood and bark-wood mixtures with the Szego mill. University of Toroto, Toroto
20. Marrs G, Mulderig B, Davio D, Burt M (2015) Feedstock Sourcing: NARA Years 1-3, Northwest Advanced Renewables Alliance, Weyerhaeuser, Federal Way, WA. https://research.libraries. wsu.edu/xmlui/handle/2376/6401?show=full, Accessed 23 Dec 2017

21. Shapiro M, Galperin V (2005) Air classification of solid particles: a review. Chem Eng Process Process Intensif 44:279-285

22. ASAE S319 (2005) Method of determining and expressing fineness of feed materials by sieving

23. Abdullah EC, Geldart D (1999) The use of bulk density measurements as flowability indicators. Powder Technol 102:151-165

24. Jankovic A, Dundar H, Mehta R (2010) Relationships between comminution energy and product size for a magnetite ore. J South Afr Inst Min Metall 110:141

25. Temmerman M, Jensen PD, Hébert J (2013) Von Rittinger theory adapted to wood chip and pellet milling, in a laboratory scale hammermill. Biomass Bioenergy 56:70-81

26. von Rittinger PR (1867) Taschenbuch der aufbereitungskunde (in German). Ernst \& Korn, Berlin

27. Kick F (1885) Das Gesetz der Proportionalem Widerstand und Seine Anwendung (Principle of Proportional Resistance and Its Application). Leipz Ger Felix, Leipzig

28. Bond FC (1952) The 3rd theory of comminution. Trans Am Inst Min Metall Eng 193:484-494

29. Di Giacomo G, Taglieri L (2009) Renewable energy benefits with conversion of woody residues to pellets. Energy 34:724-731

30. Gravelsins R, Trass O (2013) Analysis of grinding of pelletized wood waste with the Szego Mill. Powder Technol 245:189-198 